\title{
MUDANÇA EM DOIS PERÍODOS DO SÉCULO XX: INTER-RELACIONANDO ANÁLISES EM TEMPO APARENTE
}

\author{
Maria Alice TAVARES *
}

- RESUMO: À luz da sociolinguística variacionista, tomo os conectores E, Aí, DAÍ e ENTÃO como variantes da variável dependente "sequenciação retroativo-propulsora". Os dados são oriundos das seguintes fontes: (i) As vinhas da ira, romance escrito por John Steinbeck em 1939, cuja tradução brasileira, datada de 1940, apresenta marcas da fala de classes populares do Rio Grande do Sul; (ii) 48 entrevistas provenientes do Banco de Dados VARSUL de Florianópolis, que foram coletadas ao longo da última década do século XX. Tenho por objetivos: (i) buscar indícios de mudança em tempo real; (ii) buscar indícios de mudança em tempo aparente através do controle da variável social idade; (iii) inter-relacionar os resultados referentes à variável idade nos dois períodos de tempo considerados. Obtive indícios de mudança em tempo real e de mudança em tempo aparente. Além disso, fiz uma inter-relação entre os resultados referentes à variável idade no final da primeira metade do século XX e no final da segunda metade do século XX. Baseada nessa inter-relação, consegui traçar um panorama mais detalhado das mudanças possivelmente sofridas por E, AÍ, DAÍ e ENTÃO ao longo do século XX.

- PALAVRAS-CHAVE: Mudança. Tempo real. Tempo aparente. Conectores. VARSUL. As vinhas da ira.

\section{Introdução}

Abordo um fenômeno de variação e mudança linguística envolvendo, como variável dependente, uma função discursiva que denomino sequenciação retroativo-propulsora, responsável por estabelecer uma relação coesiva de sequenciação entre enunciados, de modo que o primeiro serve de base para o que será dito no segundo. A sequenciação realiza um movimento duplo: anafórico e catafórico, pois, ao mesmo tempo em que se volta para o enunciado passado como uma fonte de informações para a continuidade do discurso, direciona a atenção para um enunciado que está por vir, o qual tem por escopo. É o que tento apreender com o rótulo sequenciação retroativo-propulsora: os movimentos simultâneos de retroagir - guiando a atenção para trás - e de propulsionar - guiando a atenção para a frente. Em resumo, a sequenciação

* UFRN - Universidade Federal do Rio Grande do Norte. Departamento de Letras. Natal - RN - Brasil. 59.072-970 - aliceflp@hotmail.com. Bolsista PQ/CNPq. 
gera a expectativa de que algo novo será dito ou escrito, em continuidade e consonância com o já dado - indica que o que vem depois no discurso tem a ver com o que vem antes.

Na fala de Florianópolis (SC), os conectores E, AÍ, DAÍ e ENTÃO são as formas linguísticas que mais frequentemente desempenham a função de sequenciação retroativo-propulsora, ${ }^{1}$ e são aqui tomados como variantes. Como sequenciadores retroativo-propulsores, E, AÍ, DAÍ e ENTÃO indicam as seguintes relações semântico-pragmáticas: (i) conexão textual: sinalização da ordem pela qual as unidades conectadas sucedem-se ao longo do tempo discursivo, salientando o encadeamento de uma porção textual anterior com uma posterior (como em (1)); (ii) conexão temporal: apresentação de eventos no texto de acordo com a ordem em que ocorrem no tempo (como em (2)); (iii) conexão de causa-consequência: introdução de informações que representam consequência em relação a uma causa mencionada previamente (como em (3)). ${ }^{2}$

(1) “E eu e a S., a gente se perdeu lá, porque a gente andava sempre juntas, né? Então, tem duas descidas $\underline{\mathbf{e}}$ a gente não sabe qual a descida que é pra gente sair, $\underline{\mathbf{e}}$ eles não dão informação, tu sabes? Os paraguaios, eles não dão pra genteinformação pra gente." (AT/FLP09A). ${ }^{3}$

(2) “Tem que lavar o arroz, botar na- na- no fo- ah, não! Tem que botar a água, aí bota o óleo, bota o sal, aí bota o arroz. Deixa eu ver o que mais." (JA/FLP11J).

(3) "Talvez ela vai vender um terreno que ela ganhou e talvez ela compre um terreno e compre um cachorro pra gente, porque lá em casa não tem muito espaço, daí ela não quer comprar um cachorro". (TH/FLP07C).

1 Existem também outros conectores que desempenham a mesma função, porém menos frequentes e de distribuição diferenciada, razões pelas quais não foram incluídos neste estudo. Entre eles, o que mais se destaca é o depois (TAVARES, 2003a)

2 Nas gramáticas normativas, as relações semântico-pragmáticas em questão costumam ser incluídas sob o rótulo de "coordenação aditiva" e ilustradas com o conector E. Vejam-se alguns exemplos: "O galho partiu e o menino caiu da árvore.", "Eu li a carta e entreguei-a a Pedro." (ALI, 1969, p.105, 133); "Deram o braço e desceram a rua.", "Tio Cosme acomodava as carnes, e a besta partia a trote." (CUNHA, 1994, p.534, p.554); "Acordou e pulou da cama." " "Caiu e levantou-se." " Tomei café e saí." (SACCONI, 2008, p.335-337). Não forneci informações mais detalhadas a respeito dessas relações por uma questão de espaço, mesma razão pela qual apresentei apenas um exemplo de cada uma delas, embora tanto E quanto AÍ, DAÍ e ENTÃO as indiquem. Em Tavares (2003a, 2004, 2006a), podem ser conferidos resultados referentes ao controle das relações semânticopragmáticas como variável independente.

3 Os dados apresentados acima provêm do Banco de Dados VARSUL (Variação Linguística Urbana no Sul do Brasil). O código que segue o trecho da entrevista a identifica. Por exemplo, em (AT/FLP09) = informante AT, natural de Florianópolis (FLP), entrevista número 9. O código C indica faixa etária de 9 a 12 anos, J indica faixa etária de 15 a 21 anos, A indica faixa etária de 25 a 45 anos, e B indica faixa etária de mais de 50 anos. 
Provenientes de fontes distintas e em épocas distintas, E, AÍ, DAÍ e ENTÃO tornaram-se conectores através de processos de gramaticalização. ${ }^{4} \mathrm{O}$ E adentrou o português já na função de conector, oriundo da conjunção latina ET. O ENTÃO também já era utilizado como conector nos primórdios da língua portuguesa (séculos XIII e XIV). Quanto ao AÍ e ao DAÍ, é provável que seus usos como conectores tenham surgido em tempos mais recentes, pois, em um estudo anterior, tendo como fonte vários textos escritos em língua portuguesa e datados do século XIII ao XX, obtive dados de AÍ e de DAÍ como conectores apenas em textos escritos em português brasileiro - a partir da primeira metade do século XX, no caso de AÍ, e da segunda metade do século XX, no caso de DAÍ (TAVARES, 2003a). ${ }^{5}$ Além disso, em outro estudo, comparando conectores coordenativos na fala do português brasileiro e do português europeu, não localizei nenhum dado de AÍ e de DAÍ na fala portuguesa, o que é forte indício de que eles se desenvolveram apenas no português brasileiro (TAVARES, 2003b).

Cada conector recém-chegado passou a conviver e a competir por espaço com os demais, o que permite que sejam tomados como formas variantes na expressão da sequenciação retroativo-propulsora. ${ }^{6}$ A seguir, estão listados alguns exemplos cuja similaridade ressalta a possibilidade de uso variável de E,AII, DAİ e ENTÃO. Trata-se de ocorrências extraídas de entrevistas pertencentes ao Banco de Dados VARSUL de Florianópolis, em trechos de introdução de discurso direto, com o verbo de elocução ‘dizer' no pretérito perfeito do indicativo.

(4) 'Aí a minha mãe: 'Ah! pois é, mas eu tenho que dar baixa nessa carteira.' Aí o cara falou: 'É, mas a senhora não quer nada?' $\underline{\mathbf{E}}$ a minha mãe disse: 'Quer nada o quê?' 'É porque nós somos obrigados a vender um ônibus desses pra pagar ele, porque a- a carteira dele não está dando baixa, ninguém deu baixa, né?' " (MC/ FLP09J).

(5) "Aí no que ele chegou ali, ele me convidou pra mim ouvir música com ele. $\underline{\text { Aí }}$ eu disse: 'Ah, não, eu não vou, porque amanhã é outro dia, e eu, outro dia, tenho

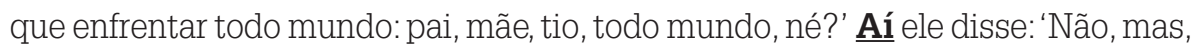
amanhã eu fico contigo.' Eu disse: 'Ah, não.' Aí eu não sabia se eu acreditava nele,

Através da gramaticalização, estratégias retóricas envolvendo itens lexicais e/ou gramaticais, inicialmente criativas e expressivas, tornam-se habituais por terem sido utilizadas recorrentemente em determinado tipo de contexto interacional. A gramática é alimentada por essa rotinização de inovações. Com base em dados do latim e das várias fases da língua portuguesa, Tavares (2003a) faz uma análise das etapas de gramaticalização de E, AÍ, DAÍ e ENTÃO como conectores.

5 Além das formas AÍ e DAÍ, também considerei, em minha busca em textos do século XIII ao XX, as variações formais HY, Y e AHI no caso de Aí, e DHI, DY, DI e DJ no caso de DAÍ. Quanto a ENTÃO, as variações formais observadas foram ENTÕ, ENTON e ENTONCE.

6 Sobre a abordagem, à luz da sociolinguística variacionista, de formas de mesma função, conferir Tagliamonte (2006). 
se eu ria, se eu chorava, se eu não- Eu não sabia a minha reação, não tem?" (SE/ FLP20A).

(6) "Ele pegou e saiu e nós estávamos conversando, daí a minha irmã disse, né? 'Ah, ele está falando assim, ele vai botar nós pra rua. Se eu trazer a carteira amanhã, ele vai ter que assinar." (JR/FLP02J).

(7) "Mas ele insistiu e disse: 'Olha, tem uma equipe de São Paulo, lá, do Professor Odair Pedroso, se for necessário nós podemos lhe mandar pra São Paulo fazer um curso.' Então eu disse: 'Se é assim, se desejam assim, eu posso tentar, se não decepcionar.' Então eu fiquei, realmente três meses em treinamento com a equipe do Professor Odair Pedroso num- no Hospital Celso Ramos. " (AC/FLP21B).

Neste texto, apresento os resultados que obtive com o controle da variável social idade em duas amostras referentes a dois períodos de tempo distintos, o final da primeira metade e o final da segunda metade do século XX. Os dados referentes à primeira amostra foram extraídos da fala de personagens do romance As vinhas da ira, tradução brasileira de The grapes of wrath, de John Steinbeck, feita em 1940. Nessa tradução, encontrei ocorrências de E, AÍ e ENTÃO como conectores sequenciadores, inclusive em contextos de uso similares, como os ilustrados em (8) e (9) a seguir. Os dados referentes à segunda amostra foram extraídos da fala de florianopolitanos nativos, em entrevistas pertencentes ao Banco de Dados do Projeto VARSUL (Variação Linguística Urbana no Sul do Brasil).

(8) “E eu perguntei: 'Por que não escreve pra ele?' $\underline{\mathbf{E}}$ ele me disse: 'Acho que eu vou, sim, talvez eu escreva. Mas se não escrever, eu queria que você avisasse o Tommy, se você ainda ficasse por aqui.' Então eu disse: 'Tá bem, eu acho que eu vou ficar ainda.' " (STEINBECK, 1940, p.47).

(9) "Willy só andava pra cima e pra baixo e 'tava com uma vergonha que lhe digo. ㅅ́, a Elsie disse: 'Eu sei porque tu veio pra cá.' " (STEINBECK, 1940, p.72).

Tenho por objetivos: (i) buscar indícios de mudança em tempo real, comparando os resultados obtidos para os dois períodos de tempo considerados; (ii) investigar a possibilidade de ocorrência de mudança em tempo aparente em cada um dos períodos de tempo considerados; (iii) propor uma estratégia para inter-relacionar os resultados referentes à variável idade em cada um desses períodos de tempo a fim de obter um panorama mais detalhado do desenvolvimento da mudança ao longo do século XX.

Como principais resultados, aponto que a comparação entre as frequências de ocorrência dos conectores E, AÍ, DAÍ e ENTÃO no final da primeira e no final da segunda metade do século XX traz indícios de mudança em tempo real: ocorre o aumento de uso dos conectores mais recentes, AÍ e DAÍ, às expensas 
dos conectores mais antigos, E e ENTÃO. Tais indícios de mudança em tempo real são refinados pelo controle da variável idade nos dois períodos de tempo em questão. Esse controle traz indícios de ocorrência de mudança em tempo aparente, e permite traçar um percurso mais detalhado das alterações de padrões de uso sofridas por E, AÍ, DAÍ e ENTÃO ao longo do século XX.

Além disso, a análise comparativa entre a distribuição etária de E, AÍ, DAÍ e ENTÃO no final da primeira e no final da segunda metade do século XX possibilita responder a questões como: (i) os rumos de mudança sugeridos pelos resultados referentes ao final da primeira metade do século XX são confirmados pelos resultados referentes ao final da segunda metade do século XX? (ii) o que se manteve estável entre um período de tempo e outro?

Nas próximas seções, abordo a questão da análise da mudança em tempo real e em tempo aparente, descrevo e discuto os procedimentos metodológicos adotados, exponho os resultados obtidos pelo controle da variável idade no final da primeira e no final da segunda metade do século XX e levanto indícios de mudança em tempo real e em tempo aparente. A seguir, proponho uma estratégia para a inter-relação dos resultados obtidos pelo controle da variável idade nos dois períodos de tempo em questão, buscando traçar um panorama mais refinado da mudança que parece ter ocorrido nos padrões de uso dos conectores E, AÍ, DAÍ e ENTÃO ao longo do século XX. Para encerrar, apresento as considerações finais e lista das referências bibliográficas.

\section{Análise da mudança em tempo real e em tempo aparente}

Foi a sociolinguística variacionista que primeiro se voltou para a face social da variação e da mudança, um dos pilares de sua constituição na década de 60, fundamentada na proposição de que era possível estudar a heterogeneidade linguística levando em conta a relação entre a língua e a sociedade, e considerando essa relação como diretamente vinculada à mudança linguística.

Labov (1994) afirma que podemos perscrutar a mudança linguística tanto em amostras do passado quanto no que ouvimos a nossa volta, pois a língua é constituída por variações e alterações que cruzam períodos de tempo. O quadro de inter-relações linguísticas delineado hoje é reflexo dos usos anteriores dados à língua por seus falantes e é a base dos usos futuros, em um contínuo de pequenos incrementos inovadores levando a grandes mudanças. Sendo assim, os indícios de mudança linguística podem ser buscados em estudos que envolvem dados de tempo real e/ou de tempo aparente.

A pesquisa em tempo real exige o rastreamento do processo histórico de mudança em diferentes épocas da língua, valendo-se o pesquisador de amostras 
orais ou, se elas não estiverem disponíveis, amostras escritas de sincronias distintas, para poder comparar os usos dados a um certo fenômeno variável ao longo do tempo. Tal análise permite observar se a variante inovadora aumentou a frequência na comunidade com o passar do tempo "real".

Se uma mudança estiver em jogo, possivelmente haverá uma correlação significativa entre a idade dos informantes e o fenômeno estudado, mapeandose diferenças nas frequências das variantes entre falantes mais jovens e mais velhos de uma mesma fatia sincrônica, o que é denominado por Labov (1972) de mudança em tempo aparente. Para Chambers (1995, p.147), essa estratégia de abordagem sincrônica à mudança pode ser considerada a "realização singular mais notável da linguística contemporânea". Fazendo coro, Bailey (2003) aponta que estudos da mudança em tempo aparente vêm tendo um grande impacto na pesquisa linguística, levando a uma crescente ampliação do conhecimento sobre as motivações e os mecanismos da mudança.

A proposta feita por Labov (1972) é que diferenças linguísticas existentes entre gerações distintas de falantes de uma mesma comunidade - diferenças em tempo aparente - refletem desenvolvimentos diacrônicos da língua - mudanças em tempo real. O esperado é que a recorrência das variantes inovadoras aumente à proporção que diminua a idade dos informantes, do que resulta uma distribuição linear crescente: de um lado da escala, temos a faixa etária mais velha, com as frequências de uso mais baixas ou mesmo com frequência zero, e do outro a faixa etária mais jovem, com as frequências de uso mais elevadas.

A possibilidade de estudo da mudança em tempo aparente depende da validade do pressuposto de que o sistema linguístico individual é estável, isto é, o vernáculo ${ }^{7}$ de um indivíduo de uma certa faixa etária permanece essencialmente o mesmo a despeito da passagem dos anos, o que permite que se compare a fala de pessoas de diferentes idades para se observar diferentes estágios da língua. A hipótese, baseada na psicologia desenvolvimentista, é que a aquisição da língua é finalizada até o final da adolescência e se mantém estável pelo resto da vida, do que resulta que, ao analisarmos a fala de uma pessoa de setenta anos hoje, temos um reflexo do sistema que estava sendo adquirido por volta dos anos quarenta, ao passo que a fala de uma pessoa de cinquenta anos nos desvela os anos sessenta. (LABOV, 1994, 1981; SILVA; PAIVA, 1996). A concepção subjacente a esse tipo de análise é a de que a mudança linguística avança em progressão geracional: uma variante inovadora que ocorre com baixa frequência na fala dos idosos ocorre com mais frequência na fala dos adultos e mais ainda na fala dos jovens, configurando, com o passar do tempo, uma mudança na comunidade de fala.

O vernáculo é "o estilo em que o mínimo de atenção é dado ao monitoramento da fala", isto é, o falante concentra mais a atenção no que fala e menos no como fala (LABOV, 1972, p.208). É a manifestação mais espontânea da língua, de onde costumeiramente emergem os dados mais sistemáticos para a análise. 
Todavia, temos de ser cuidadosos ao assumir a perspectiva de análise da mudança em tempo aparente, pois o pressuposto de fixação do sistema linguístico ao final da adolescência não é balizado em alguns casos. Exceções têm emergido de análises empíricas, envolvendo tanto mudança morfossintática quanto fonológica. Por essa razão, Labov (2001) e Kerswill (1996) alertam que a concepção de estabilidade do vernáculo após a adolescência talvez precise ser revisada ou ao menos relativizada à cada situação de variação. Adultos em torno de trinta a quarenta anos aparentemente perderam grande parte da habilidade de mudar seu sistema linguístico, mas ainda assim não se pode afirmar que possuam um sistema rígido e imutável. ${ }^{8}$ Quando os adultos modificam seus vernáculos, acompanhando pari passu a evolução linguística na comunidade de fala, a mudança não pode ser detectada por meio de uma metodologia de tempo aparente, pois as frequências de distribuição das variantes inovadoras serão semelhantes ao longo das faixas etárias, ao invés de mais intensas entre os jovens (ou seja, não haverá uma distribuição linear crescente). Na grande maioria dos casos de mudança já estudados isso não ocorre, mas as exceções exigem cautela por parte do analista, que não deve se conformar a evidências unicamente derivadas da distribuição etária.

A solução sugerida por Labov (2001), em termos de procedimentos metodológicos, é não confiar tão somente em resultados relativos à distribuição etária dos informantes como fonte para a constatação da existência ou não de um fenômeno de mudança em andamento, mas também buscar informações em fontes diversas - por exemplo, valendo-se de dados de tempo real.

Uma parte importante da investigação das origens sociais da mudança linguística levada a cabo pela sociolinguística foi a identificação dos grupos de falantes que são "responsáveis" pela disseminação das inovações. Os traços que têm sido mais relevantes para a identificação de tais grupos distribuem-se entre aqueles adstritos ao falante (como sexo e idade) e aqueles por ele adquiridos (como classe socioeconômica e escolaridade). Grupos sociais específicos, organizados de acordo com os traços supracitados, podem influir na velocidade da mudança.

A propagação da mudança depende dos valores associados às inovações linguísticas, que, em geral, não recebem valoração positiva. ${ }^{9}$ Se uma dada forma inovadora é considerada de menor status no mercado linguístico, sua utilização pelos diferentes grupos sociais pode ser influenciada por essa avaliação negativa. Por exemplo, essa forma poderá ser mais recorrente na fala de indivíduos de menor

8 Tomemos um exemplo. Modelos de mudança sonora definiram o período final para a estabilização fonológica do sistema linguístico como ocorrendo aos dezessete anos de idade. Contudo, Norberg e Sundgren (1998 apud LABOV, 2001) observaram que, no caso de algumas variáveis fonológicas, adultos jovens continuavam a avançar a mudança no início dos vinte e mesmo trinta e quarenta anos.

9 Citando Labov (2001, p.6): "As comunidades diferem na extensão com que estigmatizam as novas formas da língua, mas eu nunca encontrei ninguém que as recebesse com aplausos." 
idade e escolaridade, que costumam utilizar com maior frequência as formas de menor status, se comparados aos indivíduos de mais idade e escolaridade. Um dos fatores que possivelmente está subjacente ao grande uso de formas inovadoras por indivíduos mais jovens é a questão da marcação de identidade: falantes adolescentes tendem a tomar formas estigmatizadas e/ou inovadoras como marcas típicas do grupo de pares (LABOV, 1972, 1990; CHAMBERS, 1995; ANDROUTSOPOULOS, 2005).

\section{Procedimentos metodológicos}

\section{Final da primeira metade do século $\mathrm{XX}$}

Se há a necessidade de retroceder para períodos de tempo distantes, o acesso ao registro falado torna-se obviamente inviável, restando a opção de se recorrer à escrita. Contudo, a coleta de dados dos conectores sob estudo em textos de épocas passadas é tarefa árdua, pois, embora E seja sempre um item bastante recorrente, a frequência de aparecimento de AÍ, DAİ e ENTÃO como conectores é bastante baixa. Em busca de dados, revistei um total de quarenta textos - de vários autores e gêneros -, publicados do século XIII ao século XX (a relação completa pode ser conferida em Tavares (2003a)). Constatei que, em todos os recortes de tempo efetuados, E é sempre abundante e ENTÃO é encontradiço desde o século XIII, embora, à exceção do romance As vinhas da ira, com pouca frequência para a execução de uma análise estatística. Em contraste, as ocorrências de AÍ somente começam a aparecer no século XX e mesmo nesse período são bastante escassas. Outros pesquisadores já se defrontaram com o mesmo problema. Por exemplo, Braga (2001, p.17) aponta como "[...] dificuldade básica inerente aos estudos voltados para a trajetória de aí [...]: a inexistência de material diacrônico que fundamentasse a análise". O romance As vinhas da ira fornece, então, o que pode ser considerado uma raridade: dados suficientes de E, AÍ e ENTÃO para a realização de um estudo variacionista.

The grapes of wrath, escrito em 1939 por John Steinbeck, é um clássico da literatura norte-americana. Narra as desventuras de uma família de retirantes de Oklahoma, os Joad, que perdem para os latifundiários as terras nas quais viveram por gerações. Com um mesmo objetivo em mente, uma multidão de agricultores desempregados - incluindo os Joad - vende seus parcos bens, compra caminhões e carros caindo aos pedaços, e põe-se na estrada, percorrendo milhares de quilômetros em direção ao sonho dourado representado pelo estado das frutas abundantes, Califórnia, para o qual apontavam tentadoramente os inúmeros panfletos que, em todo país, ofertavam empregos na colheita de pêssegos, laranjas e uvas. Depois de muitas provações, a família Joad finalmente chega à Califórnia, só para constatar que o trabalho disponível - pouco e para 
poucos - não era muito diferente da escravidão pura e simples. Começa então sua odisseia em busca de melhores condições de vida, enfrentando grandes desafios e tragédias, e sempre driblando a polícia, à caça dos desordeiros inconformados com a miséria. Trata-se, enfim, de um romance-denúncia dos dramas e flagelos de um país debilitado pela grande depressão dos anos 30 . John Steinbeck, agraciado com o prêmio Nobel de literatura em 1964, recebeu, por The grapes of wrath, o Prêmio Pulitzer.

The grapes of wrath foi traduzido para o português brasileiro em 1940 por Ernesto Vinhaes e Herbert Caro, com o título de As vinhas da ira. Foi em um dos textos ainda sobreviventes dessa primeira edição do romance ${ }^{10}$ que tive a feliz surpresa de encontrar ocorrências de AÍ como conector. Em As vinhas da ira, coletei uma boa quantidade de dados não somente de AÍ, mas também de outros dois conectores - E e ENTÃO -, o que possibilitou levar a cabo análises estatísticas, embora não tenha havido nenhuma ocorrência de DAÍ como conector.

Em The grapes of wrath, os personagens falam de acordo com a "linguagem chã dos homens de sua condição" (STEINBECK, 1940, p.10), integrantes das classes socioeconomicamente desfavorecidas. Para manter o tom de oralidade e o destaque à presença de traços de língua não padrão na fala dos personagens, a tradução para o português se valeu de marcas dialetais de classes populares do estado do Rio Grande do Sul. ${ }^{11}$ Alguns dos exemplos mais ricos ficam por conta da concordância. Por exemplo, relativamente à concordância da primeira pessoa do plural com o verbo, são apresentadas duas possibilidades para cada uma das variantes - 'nós' e a 'gente':

(10) "Nós a cultivamos, fizemos ela produzir. Nascemos aqui e queremos morrer aqui." (STEINBECK, 1940, p.35).

(11) "Aquele arado, aquela grade, lembram-se? Na guerra, nós plantou mostardeiras. Tu lembra daquele camarada que diss'assim: fique rico, compre aquelas ferramenta." (STEINBECK, 1940, p.88).

(12) "Bem, - disse Pai - a gente vendeu as coisas todas lá de casa e todo mundo andou apanhando arroz na safra, até Avô". (STEINBECK, 1940, p.86).

(13) "A gente juntamo uns duzentos dólares. O caminhão custou setenta e cinco [...]". (STEINBECK, 1940, p.86).

10 Em 2001, a tradução de The grapes of wrath feita por Ernesto Vinhaes e Herbert Caro recebeu nova edição pela Editora Record.

11 Tive notícias da existência, na tradução brasileira de 1940 de The grapes of wrath, de marcas dialetais do Rio Grande do Sul, através do excelente artigo "Pronome da segunda pessoa no Sul do Brasil: tu/você/o senhor em Vinhas da ira" (MENON, 2000). 
Sobre a "audácia" dos tradutores Ernesto Vinhaes e Herbert Caro em inserir em sua tradução a linguagem popular do Rio Grande do Sul, Menon (2000, p.149) aponta que:

[...] isso não deve ter sido só "capricho" (em todos os sentidos dessa palavra) da parte dos tradutores da editora gaúcha Livraria do Globo. Provavelmente, para terem reproduzido tão fielmente esse dialeto, eram eles mesmos utentes dessa variedade, pois em nenhum momento parece haver artificialismo nas falas das personagens. Tal fato fica mais evidente em passagens onde aparecem construções mais lusitanas que brasileiras, mas, quando o dialeto gaúcho é utilizado, ele é coerente.

Portanto um bom grau de confiança pode ser depositado nas marcas dialetais inseridas na tradução de As vinhas da ira por Vinhaes e Caro, as quais parecem de fato refletir o uso real de falantes gaúchos em torno de 1940, inclusive, possivelmente, no que diz respeito aos conectores E, AÍ e ENTÃO. Por isso, creio ser possível comparar resultados referentes ao emprego de E, AÍ e ENTÃO na fala das personagens de As vinhas da ira - como reflexos do uso real no final da primeira metade do século XX - com resultados referentes ao emprego desses conectores na fala de Florianópolis - uso real no final da segunda metade do século XX.

Embora os traços dialetais presentes em As vinhas da ira sejam de fala gaúcha, acredito ser possível tomá-los como representando um estágio anterior em relação à fala florianopolitana de hoje, em virtude da proximidade geográfica dos estados do Rio Grande do Sul e de Santa Catarina. Além disso, em um estudo anterior (TAVARES, 1999b), com o objetivo de destacar semelhanças e diferenças relativamente às restrições sociolinguísticas sobre o emprego dos conectores $\mathrm{E}$ e AÍ em duas comunidades de fala brasileiras no final do século XX - Florianópolis (utilizando dados de Tavares (1999a)) e Rio de Janeiro (utilizando dados de Silva e Macedo (1989)) -, constatei que variáveis sociais (sexo, idade e escolaridade) e linguísticas (tipo de discurso e traços semântico-pragmáticos verbais) condicionadora do uso de E e de AÍ no Rio de Janeiro atuavam de modo semelhante sobre o uso dos mesmos conectores em Florianópolis (com frequências e pesos relativos bastante próximos). Tal similaridade parece evidenciar a existência de tendências gerais quanto à estratificação sociolinguística dos conectores em questão no português brasileiro de hoje, independentemente da região considerada, hipótese que pode ser estendida para as comunidades de fala gaúcha e catarinense do final da primeira metade do século XX. Assim, parto da suposição de que a distribuição etária de E, AÍ e ENTÃO em 1940, no Rio Grande do Sul, assemelhava-se à distribuição etária desses conectores na mesma época, em Santa Catarina. 
É digno de nota que os conectores mais frequentes no original americano, and e then, foram traduzidos variavelmente para a versão brasileira como E, AÍ e ENTÃO, o que ressalta o fato de terem sido percebidos, pelos tradutores do romance, como funcionalmente equivalentes. A seguir, temos exemplos da tradução de and:12

\begin{tabular}{|c|c|}
\hline $\begin{array}{l}\text { (14i) "You go right on along. Me - I'm } \\
\text { stayin'. I give her a goin'-over all night } \\
\text { mos'ly. This here's my country. Ib'long } \\
\text { here. An' I don't give a goddamn if } \\
\text { they's oranges an' grapes crowdin' } \\
\text { a fella outa bed even. I ain't a-goin." } \\
\text { (STEINBECK, 1970, p.121). }\end{array}$ & $\begin{array}{l}\text { (14ii) “-Acho que vocês devem viajar, } \\
\text { sim. Mas eu... eu fico. "Tive pensando } \\
\text { a noite toda nisso. Aqui é a minha } \\
\text { terra. E não me importa que lá na } \\
\text { Califórnia as uvas até caiam na cama } \\
\text { das pessoas. Não vou, e pronto." } \\
\text { (STEINBECK, 1940, p.115, grifo nosso). }\end{array}$ \\
\hline $\begin{array}{l}\text { (15i) "Well, we got to tear the pan off } \\
\text { an' get the rod out, an' we got to get a } \\
\text { new part an' hone her an' shim her an' } \\
\text { fit her. Good day's job." (STEINBECK, } \\
\text { 1970, p.182). }\end{array}$ & $\begin{array}{l}\text { (15ii) "- Bem, vamo tirar fora a cuba } \\
\text { de óleo, depois também o pino da } \\
\text { biela. Á́ temo que arrumar uma peça } \\
\text { substituta e limar ela e encaixar ela. } \\
\text { É trabalho pra um dia, pelo menos." } \\
\text { (STEINBECK, 1940, p.176). }\end{array}$ \\
\hline $\begin{array}{l}\text { (16i) " 'No', said Muley. 'Not that I } \\
\text { know. Las' I heard was four days } \\
\text { ago when I seen your brother Noah } \\
\text { out shootin' jackrabbits, an' he says } \\
\text { they're aimin' to go in about two } \\
\text { weeks. John got his notice he got to } \\
\text { get off.' " (STEINBECK, 1970, p.49). }\end{array}$ & $\begin{array}{l}\text { (16ii) "'Não' - afirmou Muley. - 'Tou } \\
\text { certo de que não foram. Faz quatro } \\
\text { dias, encontrei o teu irmão Noah, 'tava } \\
\text { caçando coelho, então ele me disse } \\
\text { que só iam daquI a duas semanas. Tio } \\
\text { John também foi mandado embora.' " } \\
\text { (STEINBECK, 1940, p.48). }\end{array}$ \\
\hline
\end{tabular}

Quadro 1 - Exemplos do conector AND no romance The Grapes of Wrath e suas traduções correspondentes em As Vinhas da Ira como E, AÍ e ENTÃO

Fonte: autoria própria.

Como As vinhas da ira é um romance bastante extenso, com um total de 489 páginas e vinte e quatro capítulos na edição consultada (a primeira tradução para o português brasileiro, datada de 1940), recolhi dados apenas nas 197 páginas iniciais (da página 7 à 204), nos capítulos em que a história da família Joad é contada (capítulos I, III, V, VII, IX, XII, XIV e XV). Deixei de lado os capítulos intercalados (II, IV, VI, VIII, X, XI e XIII), em que o narrador tece considerações pertinentes à narrativa, destacando aspectos históricos, geográficos, socioeconômicos, entre outros.

12 Exemplos da tradução de then como e, aí e então podem ser conferidos em Tavares (2003a). 
Estudos que empregam corpora de períodos de tempo passados não costumam fazer o controle de variáveis sociais, pois geralmente sabe-se muito pouco ou mesmo nada sobre características socioeconômicas dos autores dos textos ou dos personagens que aí ganham fala. Entretanto foi possível considerar a influência de duas variáveis sociais na análise dos dados extraídos de As vinhas da ira: idade e sexo. Neste texto, apresento apenas resultados referentes à idade.

\section{Final da segunda metade do século XX}

Os dados referentes à fala de Florianópolis provêm do Banco de Dados VARSUL (Variação Linguística Urbana na Região Sul do Brasil), que foi organizado através da documentação do português falado em áreas urbanas dos estados da Região Sul. O armazenamento de amostras da fala de habitantes de áreas urbanas dessa região tem os seguintes objetivos principais: i) oferecer à comunidade acadêmica um corpus de oralidade representativo da Região Sul; ii) promover a descrição dos vários aspectos do português falado no Sul do Brasil; iii) fornecer um corpusideal para a investigação de fenômenos de variação e mudança linguística.

Durante o primeiro estágio da coleta de dados, li a transcrição e ouvi a gravação de trinta e seis entrevistas que já estavam disponíveis para consulta no Banco de Dados VARSUL. Trata-se de entrevistas feitas com informantes florianopolitanos nativos, jovens e adultos, distribuídos homogeneamente em relação às variáveis sociais sexo, idade e escolaridade, do que resulta a seguinte estratificação em termos de características sociais: (i) três níveis de escolarização: primário, com quatro ou cinco anos de escolarização (ou o equivalente ao $5 .^{\circ}$ ou $6 .^{\circ}$ ano do ensino fundamental); ginásio, com oito anos ( $9 .^{\circ}$ ano do ensino fundamental); colegial, com onze anos ( $3 .^{\circ}$ ano do ensino médio); (ii) três faixas etárias: de 15 a 21 anos; de 25 a 45 anos; mais de 50 anos. Essas entrevistas foram coletadas no final do século XX (entre 1990 e 1996).

No segundo estágio da coleta, utilizei uma amostra suplementar de doze entrevistas com informantes florianopolitanos com idades entre 9 e 12 anos, perfazendo um total de quarenta e oito entrevistas. ${ }^{13}$ Como os conectores E, AÍ, DAÍ e ENTÃO são bastante recorrentes na fala, considerei apenas os trinta minutos finais das entrevistas, que têm cada uma cerca de sessenta minutos de duração.

Em ambas as amostras consideradas, referentes ao final da primeira metade e ao final da segunda metade do século XX, utilizei o pacote estatístico VARBRUL (PINTZUK, 1988) para cálculo de frequências, percentuais e pesos relativos.

13 As entrevistas com informantes de 9 a 12 anos foram realizadas no primeiro semestre do ano 2000 e posteriormente doadas ao Banco de Dados VARSUL. 
Realizei rodadas binárias distintas considerando cada variante como aplicação da regra, versus as demais. ${ }^{14}$

\section{Análise da mudança em tempo real}

Encontrei a seguinte distribuição dos conectores E,AÍ, DAÍ e ENTÃO no final da primeira e no final da segunda metade do século XX:

Tabela 1 - E, AÍ, DAÍ e ENTÃO - 1. ${ }^{a}$ e $2{ }^{a}$ metades do século XX

\section{1. ${ }^{\mathrm{a}}$ METADE DO SÉCULO 2. ${ }^{\mathrm{a}}$ METADE DO SÉCULO} XX XX

\begin{tabular}{ccccc}
\hline CONECTORES & Ocorrências & $\mathbf{\%}$ & Ocorrências & $\mathbf{\%}$ \\
\hline$E$ & 624 & 82 & 1.790 & 41 \\
\hline$E N T \tilde{A} O$ & 99 & 13 & 694 & 16 \\
\hline$A I ́$ & 37 & 05 & 926 & 22 \\
\hline$D A I ́$ & - & - & 890 & 21 \\
\hline TOTAL & 760 & 100 & 4.300 & 100 \\
\hline
\end{tabular}

Fonte: autoria própria.

Na primeira metade do século XX, em As vinhas da ira, E é o conector que predomina na expressão da sequenciação retroativo-propulsora, com 82\% dos dados referentes a esse período. Todavia a frequência de $\mathrm{E}$ diminuiu para 41\% na segunda metade do século XX, em Florianópolis. Em contraste, a frequência de AÍ sofreu uma elevação de 5 para 22\%, e a de ENTÃO de 13 para 16\% - e DAÍ aparece, na segunda metade do século XX, como conector em 21\% dos casos. Ou seja, na segunda metade do século XX, há, ao invés de um, quatro conectores de grande frequência. No período de cerca de sessenta anos existente entre as sincronias aqui em comparação, aconteceram, portanto, alterações de grande proporção nos padrões quantitativos de utilização dos conectores.

Em um estudo anterior, comparando corpora de fala do final do século XX do português brasileiro (PB) e do português europeu (PE) (TAVARES, 2003b), encontrei uma alta taxa de aparecimento de $\mathrm{E}$ no PE, em que o conector é responsável por 82\% das ocorrências, ao passo que, no PB, conta com 41\% das

14 Realizei também várias rodadas ternárias, no caso de As vinhas da ira, e eneárias, no caso da amostra de fala de Florianópolis. Essas rodadas confirmaram os resultados das rodadas binárias. 
ocorrências. ${ }^{15}$ Parece, então, que, em relação à grande utilização de $\mathrm{E}$, o padrão do PE atual está próximo do padrão do PB em 1940, representado pela fala dos personagens de As vinhas da ira. À semelhança do PE, em As vinhas da ira, os adversários de $\mathrm{E}$ cavam pequenos nichos em um território em que o conector mais antigo reina quase absoluto. A ampliação da utilização de AÍ e de ENTÃO, e, posteriormente, de DAÍ como conectores parece ter acarretado a retração no uso de E. Assim, a distribuição em termos de frequência dos conectores sob enfoque no final da primeira metade e no final da segunda metade do século XX se tornou bastante diferente, bem como a distribuição desses conectores no PB e no PE na atualidade. No final da segunda metade do século XX, em Florianópolis, as frequências revelam preferências de uso que estão longe das opções quase categóricas por $\mathrm{E}$ manifestadas no final da primeira metade do século XX, em As vinhas da ira.

Uma vez que rastreei indícios de mudança em tempo real levando em conta dados do final da primeira e dados do final da segunda metade do século XX, levantei a hipótese de que uma análise da distribuição de E, AÍ, DAÍ e ENTÃO em termos de estratificação etária nos dois períodos de tempo considerados poderia ser útil para a obtenção de indícios mais refinados acerca de como aconteceu, em termos de alteração gradual dos padrões de frequência de uso, a mudança em questão. Com essa finalidade, apresento, na próxima seção, os resultados que obtive para a distribuição etária de E, AÍ, DAÍ e ENTÃO.

\section{Análise da mudança em tempo aparente}

Entender os efeitos da idade sobre a língua requer entender as mudanças nas relações sociais ao longo de nossas histórias de vida. Passamos por afiliações a sucessivos grupos de referência e socialização, em estágios que, segundo Chambers (1995, p.159), podem ser sintetizados do seguinte modo: (i) na infância, o vernáculo é desenvolvido sob influência da família e dos amigos; (ii) na adolescência, as normas vernaculares sofrem aceleração sob pressão de redes densas; (ii) no início da vida adulta, a estandardização tende a se intensificar e, uma vez que os traços do socioleto estão estabelecidos na fala, eles permanecem relativamente estáveis para o resto da vida. É no período da adolescência que os indivíduos comumente sentem necessidade de, por um lado, distinguir-se dos adultos e, por outro, aproximar-se de companheiros da mesma idade ou um pouco mais velhos. Nesse processo de busca da identidade, formas já existentes na região podem ser tomadas como marcas identitárias, havendo predileção por aquelas que fogem à língua padrão.

15 Na amostra do PE, ENTÃO é responsável por 2\% das ocorrências de conectores sequenciadores, PORTANTO é responsável por $16 \%$ dessas ocorrências. 
Busquei propor, para o conjunto de personagens de As vinhas da ira, recortes etários que fossem consoantes às etapas de vida supracitadas. Contemplo, pois, quatro faixas etárias: de 9 a 12 anos (pré-adolescentes, em pleno processo de alinhamento a um grupo de amigos); de 15 a 21 anos (envolvimento em grupos adolescentes e orientação ao grupo de trabalho mais amplo); de 25 a 45 anos (emprego regular e/ou responsabilidades familiares); acima de 50 anos (diminuição da força de trabalho e aposentadoria). Identifiquei três personagens com idades entre 9 e 12 anos; quatro com idades entre 15 e 21 anos; sete entre 25 e 45 anos; dez com mais de 50 anos. Em alguns casos, a idade das personagens é claramente revelada:

Tom: "Mas logo parou, indeciso, e sentou-se sobre o estribo do lado que não era visível do restaurante. Não podia ter mais que trinta anos." (STEINBECK, 1940, p.10, grifo nosso).

Ruthie e Winfield: "De pé na carroceria, segurando-se firmemente às bordas do caminhão, vinham os outros, a pequena Ruthie, de doze anos; Winfield, de dez, selvagem, de cara suja; todos de olhar fatigado, mas excitados [...]". (STEINBECK, 1940, p.97, grifo nosso).

Em outros casos, a idade das personagens teve de ser inferida a partir de informações dadas no texto, como nos exemplos:

Muley: "O homem estacou ao ouvir o grito e a seguir foi chegando, passos apressados. Era um homem magro e não muito alto. [...] As faces de Muley eram lisas, sem a menor ruga, mas seus olhos eram os olhos truculentos de um menino mau, briguento e petulante [...]. (STEINBECK, 1940, p.47, grifo nosso).

Mãe: "Tom quedou, olhando-a. A velha era corpulenta, mas não gorda; enrijecida devido aos muitos filhos e ao muito trabalho que teve na vida. (...) Os cabelos ralos, cor de aço, estavam amarrados sobre o pescoço, formando um nó largo e bojudo". (STEINBACK, 1940, p.76, grifo nosso).

A exemplo da confiança depositada nas marcas de oralidade presentes na tradução brasileira de As vinhas da ira como representando o dialeto gaúcho real de 1940, estou supondo que a sensibilidade linguística dos tradutores do romance também tenha se manifestado na distribuição de E, AÍ e ENTÃO de acordo com os tipos sociais - em termos de idade - que mais utilizavam cada um dos conectores sequenciadores na época.

Para o conjunto de 48 informantes que, nesta pesquisa, representam a comunidade de fala de Florianópolis, propus recortes etários idênticos aos que estabeleci para as personagens de As vinhas da ira: de 9 a 12 anos (pré- 
adolescentes,); de 15 a 21 anos (adolescentes); de 25 a 45 anos (adultos jovens); acima de 50 anos (adultos mais velhos). ${ }^{16}$

Dois dentre os conectores focalizados neste estudo - AÍ e DAÍ - costumam ser considerados de menor status, isto é, trata-se de conectores que não fazem parte do conjunto de formas pertencentes à língua padrão. Sua utilização é, provavelmente, influenciada por tal avaliação negativa: AÍ e DAÍ devem ser mais recorrentes na fala dos indivíduos mais jovens, de 9 a 12 anos e de 15 a 21 anos, ao passo que os indivíduos de mais idade devem dar preferência para $\mathrm{E}$ e para ENTÃO, que não são considerados conectores de menor status. ${ }^{17}$ Pautando tal previsão, está a hipótese de que: (i) a necessidade de afirmação da identidade levaria a uma maior frequência de formas de menor status, como AÍ e DAÍ, na fala das pessoas com menos de 21 anos; (ii) o caráter estigmatizado desses conectores resultaria em sua menor recorrência na fala das pessoas com mais de 25 anos, talvez em razão de um maior envolvimento com o mercado de trabalho, em que pode haver uma certa pressão em direção ao respeito de normas da língua padrão.

Subjacente à relação entre períodos de vida e o uso de formas de statusinferior, está outra razão pela qual podemos esperar uma maior recorrência de AÍ e de DAÍ na fala dos menores de 21 anos: são esses indivíduos que tendem a angariar formas inovadoras como marcas típicas do grupo de pares. Os itens linguísticos que sofrem "discriminação" são, em geral, mais novos em relação a outras opções tidas como mais "corretas" - e por isso mesmo considerados como de menor valor. Assim, as formas tomadas como marcas identitárias pelos pré-adolescentes e/ ou adolescentes apresentam, comumente, duas propriedades correlacionadas: são relativamente recentes e, em decorrência, possuem baixo status no mercado linguístico - caso de AÍ e de DAÍ.

Conforme Labov (2001), a aquisição linguística é, em grande parte, uma transmissão de traços fonéticos e morfossintáticos de núcleos adolescentes e pré-adolescentes mais velhos a mais jovens, sobrepondo-se à base linguística transmitida pelos pais. A transmissão da mudança acontece no processo de transmissão da língua, em uma trajetória constante de inovações que são adicionadas ao vernáculo adquirido dos pais. Cada criança reflete o nível de sua aquisição inicial (do que lhe foi transmitido pelos pais), acrescido de alterações advindas do contato com irmãos e outras crianças mais velhas na comunidade local. Há, portanto, incrementos constantes nas gramáticas individuais: a experiência de cada grupo mais jovem faz a mudança avançar.

16 Embora a faixa etária '25 a 45 anos' seja bastante ampla, a maioria dos informantes que a integram se encontra entre 34 e 45 anos (nove informantes do total de doze), o que minimiza eventuais enviesamentos que uma faixa etária abarcando indivíduos de idades tão diferentes pudesse causar.

17 Sobre testes de avaliação referentes ao status dos conectores E, AÍ, DAÍ e ENTÃO, conferir Tavares (2003a, 2003c). 


\section{Final da primeira metade do século XX}

O que espero em termos da relação entre a idade dos indivíduos retratados em As vinhas da ira e o aparecimento de E, AÍ e ENTÃO é que a recorrência de AÍ, a variante mais recente dentre as encontradas no romance, aumente à proporção que diminuir a idade das personagens, já que as gerações mais jovens inclinamse a utilizar formas inovadoras e de menor status - se hoje em dia a avaliação do uso de AÍ como conector não é positiva (TAVARES, 2003a), há setenta anos atrás o conector provavelmente era ainda mais estigmatizado e mais fortemente vinculado à fala de adolescentes e pré-adolescentes.

Conforme mostram os resultados a seguir, a distribuição de E, AÍ e ENTÃO de acordo com a estratificação etária é passível de diagnosticar uma mudança em tempo aparente na comunidade de fala do final da primeira metade do século XX representada pelas personagens de As vinhas da ira.

Tabela 2 - Distribuição de E, AÍ e ENTÃO quanto à idade na 1. a metade do século XX

\begin{tabular}{|c|c|c|c|c|c|c|c|c|c|}
\hline & \multicolumn{3}{|c|}{$E$} & \multicolumn{3}{|c|}{$A \dot{I}$} & \multicolumn{3}{|c|}{ ENTÃO } \\
\hline IDADE & Ap./Tot. & $\%$ & PR & Ap./Tot. & $\%$ & PR & Ap./Tot. & $\%$ & PR \\
\hline 9 a 12 anos & $8 / 15$ & 53 & 0,31 & $2 / 15$ & 13 & 0,61 & $5 / 15$ & 33 & 0,63 \\
\hline 15 a 21 anos & $78 / 96$ & 81 & 0,54 & $8 / 96$ & 8 & 0,62 & $10 / 96$ & 10 & 0,39 \\
\hline 25 a 45 anos & $339 / 404$ & 84 & 0,54 & $23 / 404$ & 6 & 0,55 & $42 / 404$ & 10 & 0,43 \\
\hline+ de 50 anos & $172 / 219$ & 79 & 0,43 & $5 / 219$ & 2 & 0,35 & $42 / 219$ & 19 & 0,67 \\
\hline TOTAL & $597 / 734$ & 82 & & $38 / 734$ & 5 & & $99 / 13$ & 13 & \\
\hline
\end{tabular}

Fonte: autoria própria.

E é o conector maciçamente mais frequente, com $82 \%$ das ocorrências em geral, e de 79 a 84\% das ocorrências entre os grupos de falantes com mais de 15 anos. Contudo, os pesos relativos de 0,54 apontam um condicionamento maior por parte dos grupos etários intermediários. Em contraste, entre os préadolescentes, a utilização de $\mathrm{E}$ é mais restrita, havendo um pico de desuso (frequência de 53\% e peso relativo de 0,31). Esse seria um indício de que haveria, futuramente, uma presença gradativamente menor de $\mathrm{E}$ a cada geração de falantes vindoura?

Percebe-se uma relação direta entre a diminuição da idade e o aumento de uso de AÍ, tanto em termos de frequências quanto de pesos relativos. No entanto, a faixa etária mais jovem, embora tenha apresentado a frequência mais alta de AÍ (13\%), recebeu um peso relativo um ponto mais baixo $(0,61)$ que a faixa etária precedente $(0,62)$, provavelmente em razão da maior recorrência de ENTÃO entre os pré-adolescentes. 
ENTÃO destaca-se entre as gerações mais velha, com frequência de 19\% e peso relativo de 0,67 , e mais jovem, com frequência de $33 \%$ e peso relativo de 0,63. Seu favorecimento na fala pré-adolescente poderia ser tomado como um indício de mudança, prevendo-se um emprego maior desse conector entre os falantes mais jovens com o passar do tempo. No entanto, como ENTÃO também predomina na fala dos indivíduos com mais de 50 anos, e é desfavorecido entre os indivíduos de 15 a 21 anos e de 25 a 45 anos, torna-se difícil tecer previsões quanto ao destino desse conector.

Diferentemente, a maior opção por AÍ manifestada a cada nova geração é uma evidência mais forte de mudança linguística em andamento no sentido de que esse conector poderia vir a ocupar pouco a pouco o espaço de E e de ENTÃO.

Não se pode deixar de mencionar, ademais, a existência de um grande acréscimo de uso de AÍ entre os dois grupos etários mais velhos: esse conetor passa de uma frequência de $2 \%$ e peso relativo de 0,35 para uma frequência de $6 \%$ e peso relativo de 0,55 , o que é um indício de que a geração que contava com 25 a 45 anos em 1940 pode ter apresentado um pico de uso de Aí em seu período de adolescência. Ou seja, um período de mudança mais vigorosa para AÍ poderia ter ocorrido por volta de 1920.

Enfim, podemos interpretar os resultados relativos ao controle da idade das personagens de As vinhas da ira como indícios da ocorrência de um processo de mudança, segundo o qual Aí, o conector mais recente entre os utilizados nesse romance, teria seu uso gradativamente incrementado a cada nova geração de falantes e, talvez como contraparte, E teria seu uso diminuído. Já para ENTÃO é mais difícil tecer previsões, pois o conector recebe destaque na fala das personagens mais jovens, mas também na fala das mais idosas.

\section{Final da segunda metade do século XX}

A hipótese para a distribuição etária dos conectores E, AÍ, DAÍ e ENTÃO no final da segunda metade do século XX, em Florianópolis, é que o aparecimento das variantes mais recentes, AÍ e DAÍ, deve aumentar à proporção que diminui a idade dos falantes, o que pode ser tomado como indício de que tais conectores têm seu uso acelerado pelas gerações mais jovens, em um processo de mudança linguística. 
Tabela 3 - Distribuição de E, AÍ, DAÍ e ENTÃO quanto à idade na 2. . metade do século XX

\begin{tabular}{|c|c|c|c|c|c|c|c|c|c|c|c|c|}
\hline \multirow[b]{2}{*}{ IDADE } & \multicolumn{3}{|c|}{$E$} & \multicolumn{3}{|c|}{$A \dot{I}$} & \multicolumn{3}{|c|}{$D A \dot{I}$} & \multicolumn{3}{|c|}{$E N T \tilde{A O O}$} \\
\hline & Ap./Tot. & $\%$ & PR & Ap./Tot. & $\%$ & PR & Ap./Tot. & $\%$ & PR & Ap./Tot. & $\%$ & PR \\
\hline 09 a 12 anos & $300 / 1.146$ & 26 & 0,39 & $144 / 1.146$ & 13 & 0,24 & $686 / 1.146$ & 60 & 0,91 & $16 / 1.146$ & 1 & 0,12 \\
\hline 15 a 21 anos & $479 / 1.064$ & 45 & 0,51 & $310 / 1.064$ & 29 & 0,64 & $161 / 1.064$ & 15 & 0,64 & $114 / 1.064$ & 11 & 0,36 \\
\hline 25 a 45 anos & $488 / 1.113$ & 44 & 0,52 & $290 / 1.113$ & 26 & 0,60 & $29 / 1.113$ & 3 & 0,21 & $306 / 1.113$ & 27 & 0,74 \\
\hline+ de 50 anos & $523 / 977$ & 54 & 0,59 & $182 / 977$ & 19 & 0,40 & $14 / 977$ & 1 & 0,13 & $258 / 977$ & 26 & 0,77 \\
\hline TOTAL & $1.790 / 4.300$ & 41 & & $926 / 4.300$ & 22 & & $890 / 4.300$ & 21 & & $694 / 4.300$ & 16 & \\
\hline
\end{tabular}

Fonte: autoria própria.

O conector E é o mais frequente, sendo responsável por 41\% dos dados, e possuindo alta taxa de recorrência em três dos grupos etários controlados. Os falantes com mais de 50 anos são os que mais tendem à utilização de E, com frequência de $54 \%$ e peso relativo de 0,59. Esse conector também recebe destaque na fala dos indivíduos de 25 a 45 anos e dos adolescentes, e tem uso mais restrito apenas entre os pré-adolescentes.

AÍ é favorecido na fala dos adolescentes e dos indivíduos de 25 a 45 anos, com frequências de $29 \%$ e $26 \%$, e pesos relativos de 0,64 e 0,60, respectivamente. Quanto a DAÍ, os dois grupos de falantes mais jovens tendem ao uso desse conector, com frequências de 15\% e 60\% e pesos relativos de 0,64 e 0,91. Contrastivamente, os dois grupos de falantes mais velhos inclinam-se fortemente a seu desfavorecimento, com frequências de 1\% e 3\% e pesos relativos de 0,13 e 0,21.

Os grupos que mais fazem uso de ENTÃO são aqueles referentes a indivíduos maiores de 25 anos, com frequências de $26 \%$ e $27 \%$ e pesos relativo de 0,77 e 0,74 . Comparativamente, indivíduos com menos de 21 anos utilizam pouco esse conector, com frequências de 1\% e 11\% e pesos relativos de 0,12 e 0,36.

Portanto, as hipóteses propostas para o controle da variável idade na amostra de Florianópolis foram atestadas: os conectores mais recentes e de menor status, AÍ e DAÍ, estão associados aos falantes mais jovens, ao passo que os mais antigos e não estigmatizados, E e ENTÃO, estão associados aos falantes mais velhos. As exceções são a inesperada alta frequência (26\%) e o peso relativo elevado $(0,60)$ referente ao emprego de AÍ pelos indivíduos de 25 a 45 anos, e a sua baixa frequência $(13 \%)$ e o peso relativo diminuto $(0,24)$ referente ao emprego desse conector pelos os pré-adolescentes.

Uma vez que foi constatada uma correlação significativa entre a idade dos informantes e o uso de E, AÍ, DAÍ e ENTÃO, a possibilidade de que uma mudança esteja em progresso é grande: DAÍ, a cada geração, vem ocupando um espaço maior na indicação da sequenciação retroativo-propulsora. Analisemos com maior detalhe...

Com base em diversos estudos que observaram haver uma utilização intensa de formas inovadoras por indivíduos em torno de dezesseis a vinte anos de idade, 
Labov (2001) defende a possibilidade de existência de um pico de uso dessas formas no período final da adolescência. Depois desse pico de uso, teria lugar uma retração constante da frequência de utilização das variantes inovadoras à medida que aumenta a idade dos informantes, ocorrendo uma distribuição linear decrescente a partir das faixas etárias adultas. Precedendo o pico de uso na fala adolescente, haveria um uso ainda elevado, mas menor, das formas em questão, por parte dos indivíduos com menos de dezesseis anos.

Como contraparte, podemos esperar um pico de desuso, entre os adolescentes, de variantes mais antigas. No caso dos conectores E, AÍ, DAİ e ENTÃO, as variantes mais antigas e de maior status, E e ENTÃO, parecem estar perdendo porções do território a cada geração, o que é evidenciado pela distribuição etária decrescente: quanto mais jovens os falantes, menor a utilização de E e de ENTÃO. Contudo a retração do uso de E acontece de modo mais suave, verificando-se a existência de um declive maior de desuso apenas na fala dos pré-adolescentes. Já os desenvolvimentos de ENTÃO em termos geracionais apresentam um pico de recalque de uso que se inicia entre os adolescentes e se acentua entre os pré-adolescentes.

E quanto a AÍ e a DAÍ? A distribuição de AÍ pelas três faixas etárias mais velhas caracteriza-se por um aumento de frequência acompanhando a diminuição da idade (da frequência de 19\% e peso relativo de 0,40 entre os indivíduos com mais de 50 anos a frequência de $29 \%$ e peso relativo de 0,64 entre os adolescentes). Configura-se, portanto, uma distribuição linear crescente que poderia ser interpretada, a despeito da ausência de um pico mais intenso de uso na adolescência, como indício de mudança em progressos, no sentido de que as gerações vindouras optariam cada vez mais por AÍ para indicar a sequenciação retroativo-propulsora. Contudo, os resultados para o grupo mais jovem, de 9 a 12 anos, frustram essa interpretação: a utilização do conector sofre uma grande contração, passando da frequência de $29 \%$ e do peso de 0,64 referentes à faixa anterior, para $13 \%$ e 0,24.

Silva e Macedo (1996), com base em dados de informantes cariocas, analisaram a influência da idade sobre o uso de AÍ e concluíram que, quanto mais jovem o falante, maior é o uso do conector em questão. Os pesos relativos atribuídos a cada uma das faixas etárias consideradas foram: de 7 a 14 anos =0,70; de 15 a 25 anos $=0,60$; de 26 a 50 anos = 0,40; mais de 50 anos = 0,30. Foi obtida, portanto, uma distribuição linear crescente: 0 aparecimento de AÍ aumenta à medida que diminui a idade dos informantes. Ou seja, no Rio de Janeiro, AÍ parece não ter tido interrompida sua trajetória de aumento em progressão geracional, ocupando o conector mais e mais terreno a cada novo grupo etário. ${ }^{18}$

18 Silva e Macedo (1996) utilizaram dados provenientes da "Amostra Censo". 
Em Florianópolis, entre os indivíduos de 15 a 21 anos, a frequência de AÍ, de $29 \%$, já é a segunda maior (nessa faixa etária, ele perde apenas para E, com $45 \%$ ), e o peso relativo, 0,64, é semelhante ao atribuído à faixa etária correspondente no estudo de Silva e Macedo (indivíduos de 15 a 25 anos), 0,60. Se o processo de incremento de uso a cada nova geração tivesse continuado em Florianópolis, AÍ poderia ter tido seu emprego aumentado na fala dos pré-adolescentes. Nesse caso, talvez apresentasse um peso relativo similar ao de Aí carioca no grupo de 7 a 14 anos $(0,70)$. Contudo, no grupo florianopolitano correspondente (de 9 a 12 anos), um dos conectores - o mais recente - aparece tomando espaço dos demais conectores.

O emprego de DAÍ como conector é baixo entre os florianopolitanos com mais de 25 anos. Já entre os adolescentes, observa-se um pico de uso, em comparação com as duas faixas mais velhas: a frequência de DAÍ atinge os 15\% e o peso relativo é 0,64. Há um pico de uso ainda maior entre os pré-adolescentes, com frequência de $60 \%$ e peso relativo de 0,91. Parece que os adolescentes de Florianópolis adotaram DAÍ como marca identitária e o transmitiram a falantes cada vez mais jovens, o que culminou em sua utilização intensa entre os pré-adolescentes.

Labov (2001) prevê que os picos de mudança acontecem na fala de indivíduos no final da adolescência, com idades em torno de 16 a 20 anos. No caso sob enfoque, tal não se verifica: os maiores picos de uso e de desuso de E, AÍ, DAÍ e ENTÃO encontram-se na faixa etária de 09 a 12 anos, e não na faixa de 15 a 21 anos. As razões que motivam os indivíduos, na pré-adolescência, a superdisseminarem formas inovadoras e de baixo status devem ser as mesmas que motivam os adolescentes. As pessoas de 9 a 12 anos já estão em uma fase de busca e afirmação da identidade, procurando aproximar-se do grupo de pares. Nesse processo, podem adotar formas linguísticas como marcas identitárias, reforçando um modo de falar "jovem", em oposição a um modo de falar "adulto" (ou "velho"). ${ }^{19}$

Podemos interpretar os números apresentados na tabela 3 como significando que AÍ tomou um pouco do espaço de E no grupo de 25 a 45 anos (a frequência daquele aumentou, a deste diminuiu) e outro tanto de E e de ENTÃO no grupo de 15 a 21anos. Contudo, uma possível mudança em direção ao predomínio de Aí na indicação de sequenciação retroativo-propulsora foi interrompida em razão da grande disseminação de DAÍ. O maior atingido pelo avanço de DAÍ, no entanto,

19 Além de ser uma marca típica da fala dos membros mais jovens da comunidade florianopolitana, o uso de DAÍ como conector pode ser uma marca regional. Nesse caso, tratar-se-ia de um item linguístico indicando que seu usuário é, provavelmente, um adolescente ou pré-adolescente residente em Florianópolis (TAVARES, 2006b). Alguns depoimentos informais colhidos de linguistas pertencentes a comunidades de fala de outras cidades (Rio de Janeiro, São Paulo, Salvador e Natal) apontam fortemente nessa direção, afirmando que o grande uso de DAÍ em Florianópolis chama a atenção e que não têm observado tão grande recorrência desse conector em suas comunidades e muito menos na fala de adolescentes e pré-adolescentes. Ou seja, há bons indícios de que o grande uso de DAÍ como conector em Florianópolis represente um processo de intensa disseminação de uma marca identitária típica de adolescentes e pré-adolescentes florianopolitanos. 
parece ter sido ENTÃO, cuja evolução reflete, como imagem de espelho, a de DAÍ: o pico de uso - altíssimo - de ENTÃO acontece entre os falantes adultos e com mais de 50 anos e o de DAÍ - ainda mais alto - entre os falantes adolescentes e préadolescentes. À medida que a utilização de DAÍ aumenta, a de ENTÃO diminui.

É possível que os pré-adolescentes florianopolitanos tenham diminuída a taxa de aparecimento de DAÍ em sua fala à medida que amadurecerem. Conforme Labov (2001), é previsto que ocorra, nos processos de mudança, após o pico de uso da forma inovadora, uma diminuição de sua utilização: ela é incorporada, ainda com altos índices de frequência, à gramática dos falantes do grupo etário em que teve seu uso fortemente acelerado, mas passa a ser menos frequente, em comparação com a fase de pico de uso. O processo de mudança torna-se menos radical: passa a haver uma distribuição linear decrescente gradual nas faixas etárias adultas, representadas pelos indivíduos que levaram a forma inovadora a seu ápice quando adolescentes. Ou seja, DAÍ poderá realmente superar os demais conectores em termos de frequência de uso com o passar do tempo, mas com uma velocidade menor do que a que seria prevista considerando-se somente seu estágio de pico de uso na fala dos pré-adolescentes florianopolitanos no final do século XX.

\section{Inter-relacionando análises em tempo aparente}

O padrão de distribuição etária de E, AÍ, DAÍ e ENTÃO obtido no final da primeira metade do século XX, em As vinhas da ira, pode ser entendido como representando uma etapa anterior de variação e de mudança em relação ao padrão de distribuição etária obtido no final da segunda metade do século XX, em Florianópolis. Assim, a comparação entre esses padrões em cada uma das fatias sincrônicas em questão, além de permitir observar o que pode ter permanecido estável ao longo do tempo, pode fornecer indícios mais refinados sobre a mudança ocorrida. Por exemplo, é possível obter ou não a confirmação, no final da segunda metade do século XX, de alterações previsíveis a partir do padrão de distribuição etária verificado no final da primeira metade do século XX.

A maior diferença entre a distribuição dos conectores E, AÍ, DAÍ e ENTÃO nos dois períodos de tempo considerados é o aparecimento e a grande disseminação de DAÍ (empregado pelos pré-adolescentes da segunda metade do século XX em 60\% das ocorrências), conector que, se já era utilizado em 1940, deveria ser pouco recorrente e, talvez por isso, não tenha aparecido na fala das personagens de As vinhas da ira. Como resultado da grande disseminação de DAÍ na fala dos mais jovens, a opção por ENTÃO se tornou tão infrequente que, conservando-se as tendências de uso atuais, o conector corre o risco de desaparecer na fala de Florianópolis. Essas são grandes mudanças tecidas 
entre o final da primeira e o final da segunda metade do século XX, e que não poderiam ter sido previstas com base na análise dos fenômenos de variação e de mudança por tempo aparente na primeira metade do século XX, uma vez que, entre os dados referentes a essa sincronia, não há sequer uma ocorrência de DAÍ como conector.

Em contraste, a comparação da distribuição de E, AÍ e ENTÃO no final da primeira e no final da segunda metade do século XX permite a confirmação e/ ou a refutação das previsões relativas aos desenvolvimentos futuros desses três conectores, feitas a partir dos resultados obtidos para a amostra referente à primeira metade do século XX. A diferença entre os períodos de tempo em causa que mais salta aos olhos é a da recorrência. Como já apontamos quando da análise em tempo real, a frequência geral de E diminuiu de $82 \%$ na primeira metade do século XX para 41\% na segunda metade, a de AÍ sofreu uma elevação de 5 para 22\% e a de ENTÃO de 13 para 16\% - e DAÍ é responsável por 21\% dos casos no final do século XX. O aumento do uso de AÍ e de ENTÃO e a diminuição do uso de $\mathrm{E}$ foram possibilidades levantadas quando da análise da distribuição dos conectores em tela na primeira metade do século XX.

Todavia, comparando os resultados referentes ao controle da variável idade em dois períodos de tempo distintos, é possível obter indícios mais refinados acerca da mudança linguística. Como salientei anteriormente, resultados encontrados por estudos variacionistas indicam que adquirimos grande parte da língua através de nossas experiências em situações de comunicação transcorridas da infância até o final da adolescência, tendendo a conservar por toda a vida os padrões linguísticos conforme experienciados nesse período.

Adotando-se essa hipótese, é possível reconstituir a mudança considerandose não apenas dois períodos de tempo, o final da primeira e o final da segunda metade do século XX, mas diversas etapas de alterações ao longo do século XX. Como? Os informantes florianopolitanos do final da segunda metade do século XX que contavam, nessa época, com idades superiores a 50 anos eram crianças ou pré-adolescentes por volta de $1940,{ }^{20}$ o ano em que As vinhas da ira foi traduzido para o português. Em consequência, a distribuição de E, AÍ e ENTÃO na fala do grupo etário mais idoso de Florianópolis pode guardar semelhanças com sua distribuição na fala das personagens de 9 a 12 anos do romance, que são aqui tomados como representando os pré-adolescentes do final da primeira metade do século XX. Vejamos:

20 As entrevistas com os informantes florianopolitanos adultos foram gravadas em 1990. Um informante de 60 anos na época tinha 10 anos em 1940. 


\begin{tabular}{|c|c|c|c|}
\hline Período de tempo & E & AÍ & ENTÃo \\
\hline 1. ${ }^{\mathrm{a}}$ metade do século XX & $53 \%$ & $13 \%$ & $33 \%$ \\
\hline 2. $^{\mathrm{a}}$ metade do século XX & $54 \%$ & $19 \%$ & $26 \%$ \\
\hline
\end{tabular}

Quadro 1- E, AÍ e ENTÃO na fala de personagens de 9 a 12 anos, no final da $1 .^{a}$ metade do século XX, e na fala de florianopolitanos com mais de 50 anos, no final da 2. ${ }^{a}$ metade do século XX

Fonte: autoria própria.

É grande a semelhança na distribuição de E, AÍ e ENTÃO na fala dos pré-adolescentes no final da primeira metade do século XX e na fala dos florianopolitanos com mais de 50 anos no final da segunda metade do século XX. Essa distribuição é um indício de que os padrões de frequência de uso dos conectores sob enfoque adquiridos por pré-adolescentes em torno de 1940 podem ter sido preservados por eles desde então.

A organização das frequências de uso de E, AÍ e ENTÃo de acordo com os grupos etários considerados no final da primeira e no final da segunda metade do século XX permite a obtenção de um panorama da possível evolução do uso de cada conector através de linhas iniciadas em torno de 1900 (época em que as personagens do romance com mais de 50 anos teriam sido pré-adolescentes) e que percorrem um trajeto de alterações que aconteceram em um período de cerca de cem anos, desembocando nos dias atuais, com a distribuição de E, AÎ́ e ENTÃO na fala dos pré-adolescentes florianopolitanos. A título de comparação, foi incluída uma linha para DAÍ, com base nos únicos resultados disponíveis para ele - os referentes ao final do século XX.

As frequências de uso dos conectores E, AÍ, DAÍ e ENTÃo por grupo etário estão assim ordenadas no Quadro 2: personagens com mais de 50 anos $\rightarrow$ personagens de 25 a 45 anos $\rightarrow$ personagens de 15 a 21 anos $\rightarrow$ personagens de 9 a 12 anos / florianopolitanos com mais de $\mathbf{5 0}$ anos (que teriam de 9 a 12 anos em 1940, ou um pouco menos, ou um pouco mais) $\rightarrow$ florianopolitanos de 25 a 45 anos (que representam a geração seguinte à que contava com idades entre 9 e 12 anos em 1940) $\rightarrow$ florianopolitanos de 15 a 21 anos $\rightarrow$ florianopolitanos de 09 a 12 anos.

O esquema traçado no Quadro 2 mostra as distribuições etárias de E, AÍ, DAÍ e ENTÃO no final da primeira e no final da segunda metade do século $\mathrm{XX}$, inter-relacionando essas duas distribuições e, portanto, inter-relacionando resultados referentes a duas análises em tempo aparente, aquela da primeira metade e aquela da segunda metade do século XX. Daí resultam, para cada conector, duas linhas de mudança em tempo aparente que encaixam uma na outra em torno de 1940. Esse encaixamento é motivado pela hipótese de a fala 
dos florianopolitanos com mais de 50 anos refletir a fala dos indivíduos de 9 a 12 anos em As vinhas da ira.

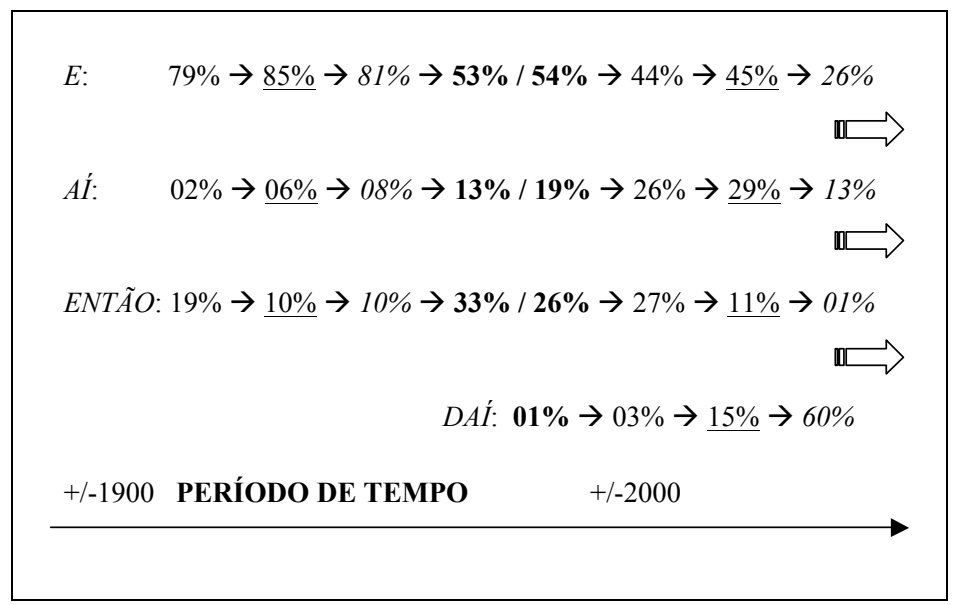

Quadro 2 - Inter-relação das frequências de uso dos conectores E, Aİ, DAÍ e ENTÃO na fala de indivíduos de diferentes faixas etárias no final da $1{ }^{a}{ }^{a}$ e no final da $2{ }^{a}$ metade do século XX

Fonte: autoria própria.

O Quadro 2 representa, assim, um possível panorama da evolução das frequências de uso dos conectores E, AÍ, DAÍ e ENTÃO ao longo do século XX. Nesse panorama, observa-se que a tendência manifestada por $E$, no final da primeira metade do século XX, de retração de uso nas gerações mais novas, segue seu curso na segunda metade do século XX, em que o conector chega à frequência de $26 \%$ na fala dos pré-adolescentes. Aí deu continuidade a sua trajetória de extensão de uso em progressão geracional, que já transparece na primeira metade do século XX, e que só foi interrompida na segunda metade do século pelos pré-adolescentes, que tomaram DAÍ como marca identitária e o têm superutilizado, às expensas dos demais conectores.

Por sua vez, ENTÃO aparenta estabilidade na fala dos florianopolitanos com mais de 25 anos, com frequências de $26 \%$ e $27 \%$, próximas da frequência dos pré-adolescentes em As vinhas da ira, de 33\%. Contudo, o conector sofre influência do maior uso de AÍ e de DAÍ na fala adolescente em Florianópolis, tendo diminuída a sua taxa de aparecimento para 11\%, e, posteriormente, sofre influência do alto uso de DAÍ na fala pré-adolescente, tendo ainda mais diminuída a sua taxa de aparecimento, desta vez para apenas 1\%. DAÍ, com frequências baixas entre os florianopolitanos com mais de 25 anos (em torno de $2 \%$ ), passa por um pico de elevação de uso entre os adolescentes, atingindo o patamar de 15\%, e, já na geração subsequente, torna-se o conector mais frequente, detendo $60 \%$ das ocorrências. 


\section{Considerações finais}

A inter-relação da distribuição etária dos conectores E, AÍ e ENTÃO no final da primeira metade do século XX, em As vinhas da ira, com a distribuição etária desses mesmos conectores, incluindo ainda a distribuição do conector DAÍ, no final da segunda metade do século XX, em Florianópolis, permitiu que fossem traçados de forma mais detalhada possíveis etapas do desenvolvimentos de uma grande mudança nos padrões de frequência de uso desses conectores ao longo do século XX. Isso não teria sido possível se os resultados obtidos nas duas análises em tempo tivessem sido tomados isoladamente, ao invés de inter-relacionados.

A inter-relação de resultados referentes a análises em tempo aparente pode ser considerada, portanto, uma estratégia de observação de mudança em tempo aparente possível de ser utilizada para a obtenção de indícios de mudança linguística com um maior grau de refinamento quando estes não estão diretamente disponíveis em tempo real.

TAVARES, M. A. Linguistic change in two periods of the $20^{\text {th }}$ century: interrelating apparent time analyses. Alfa, Araraquara, v.55, n.2, p.393-421, 2011.

- ABSTRACT: Under the light of Labovian Sociolinguistics, I take the Brazilian Portuguese connectors E, AÍ, DAÍ, and ENTÃO as variants of the dependent variable "retroactive-propeller sequenciation". The data come from the following sources: (i) "The grapes of wrath", an novel written by John Steinbeck in 1939, the 1940 Brazilian Portuguese translation of which is marked by spoken language traits of the working classes from Rio Grande do Sul (RS), the most southern Brazil State; (ii) 48 interviews from the VARSUL Data Base of Florianópolis (the capital of Santa Catarina State), which were collected during the last decade of the $20^{\text {th }}$ century. My goal are: (i) to seek evidence of change in real time, (ii) to seek evidence of change in apparent time by controlling the social variable 'age', (iii) to interrelate the results regarding the variable 'age' in both periods of time. The results present evidences of change in both real time and apparent time. Moreover, I set up an inter-relationship between the results regarding the variable 'age' at the end of the first half of the $20^{\text {th }}$ century and at the end of the second half of the $20^{\text {th }}$ century. Based on this inter-relationship, I was able to trace a more detailed picture of the changes the connectors E, AÍ, DAÍ, and ENTÃO possibly underwent throughout the $20^{\text {th }}$ century.

- KEYWORDS: Linguistic change. Real time. Apparent time. Connectors. VARSUL. The grapes of wrath.

\section{REFERÊNCIAS}

ALI, S. Gramática secundária da língua portuguesa. 8. ed. São Paulo: Melhoramentos, 1969. 
ANDROUTSOPOULOS, J. Research on youth language. In: AMMON, U. et al. (Ed.). Sociolinguistics/Soziolinguistik. an international handbook of the science of language and society/ein internationales Handbuch zurWissenschaft von Sprache und Gesellschaft. Berlin: Mouton de Gruyter, 2005. p.1496-1505.

BAILEY, G. Real and apparent time. In: CHAMBERS, J. K.; TRUDGILL, P.; SHILLINGESTES, N. (Ed.). The handbook of language variation and change. Cambridge: Blackwell, 2003.

BRAGA, M. L. Aí e então e a hipótese da trajetória universal. In: NEVES, M. H. M. (Org.). Descrição do português: definindo rumos de pesquisa. Cultura Acadêmica, 2001. p.11-24.

CHAMBERS, J. K. Sociolinguistic theory: linguistic variation and its social significance. Cambridge: Blackwell, 1995.

CUNHA, C. F. da. Gramática da língua portuguesa. 12. ed. Rio de Janeiro: FAE, 1994.

KERSWILL, P. Children, adolescence, and language change. Language Variation and Change, Cambridge, v.8, n.2, p.177-202, 1996.

LABOV,W. Principles of linguistic change: social factors. Oxford: Blackwell, 2001. . Principles of linguistic change: internal factors. Oxford: Blackwell, 1994. . The intersection of sex and social class in the course of linguistic change. Language Variation and Change, Cambridge, v.2, n.2, p.205-254, 1990.

What can be learned about change in progress from synchronic description? In: SANKOFF, D.; CEDERGREN, H. (Ed.). Variation omnibus. Edmonton: Linguistic Research, 1981. p.177-199.

1972.

. Sociolinguistic patterns. Philadelphia: University of Pennsylvania Press,

MENON, O. P. S. Pronome de segunda pessoa no sul do Brasil: tu/ você / o senhor em Vinhas da ira. Letras de Hoje, Porto Alegre, v.35, n.1, p.121-164, 2000.

PINTZUK, S. VARBRUL program. Philadelphia: University of Pennsylvania, 1988. Mimeografado.

PROJETOVARSUL. Variação Linguística na Região Sul do Brasil: banco de dados. Disponível em: <http://varsul.cce.ufsc.br/>. Acesso em: 14 ago. 2010.

SACONNI, L. A. Novíssima gramática ilustrada. São Paulo: Nova Geração, 2008. SILVA, G. M. O.; MACEDO, A. V.T. de. Análise sociolinguística de alguns marcadores conversacionais. In: MACEDO, A. V. T. de; RONCARATI, C. N.; MOLLICA, M. C. (Org.). Variação e discurso. Rio de Janeiro: Tempo Brasileiro, 1996. p.11-49. 
Análise sociolinguística de alguns marcadores conversacionais. 1989. V Relatório de Pesquisa: Projeto "Mecanismos funcionais de uso linguístico" Universidade Federal do Rio de Janeiro, Rio de Janeiro, 1989.

SILVA, G. M. O.; PAIVA, M. da C. Visão de conjunto das variáveis sociais. In: SILVA, G. M. O.; SCHERRE, M. M. P. (Org.). Padrões sociolinguísticos: análise de fenômenos variáveis do português falado na cidade do Rio de Janeiro. Rio de Janeiro: Tempo Brasileiro, 1996. p.335-378.

STEINBECK, J. The grapes of wrath. New York: Penguin, 1970.

As vinhas da ira. Tradução de Emesto Vinhaes e Herbert Caro. Porto Alegre: Livraria do Globo, 1940.

TAGLIAMONTE, S. A. Analysing sociolinguistic variation. Cambridge: Cambridge University Press, 2006.

TAVARES, M. A. O papel da marcação na expressão variável da sequenciação na fala de Florianópolis. In: VANDRESEN, P. (Org.). Variação, mudança e contato linguístico no português da região sul. Pelotas: EDUCAT, 2006a. p.51-76.

. Abordagem pancrônica à gramaticalização de DAÍ como conector. Signun: estudos da linguagem, Londrina, v.9, n.2, p.219-251. 2006b.

. Reflexos da fala do Rio Grande do Sul em 1940: uma análise sociofuncionalista em "As Vinhas da Ira". In: CHRISTIANO, M. E. A.; SILVA, C. R.; HORA, D. (Org.). Funcionalismo e gramaticalização: teoria, análise, ensino. João Pessoa: Ideia, 2004. p.95-130.

A gramaticalização de E, AÍ, DAÍ e ENTÃO: estratificação/variação e mudança no domínio funcional da sequenciação retroativo-propulsora de informações - um estudo sociofuncionalista. 2003. 307f. Tese (Doutorado em Linguística) - Universidade Federal de Santa Catarina, Florianópolis, 2003a.

Condicionamentos linguísticos e sociais sobre a sequenciação de informações no português oral d'aquém e d'além mar: mudança em progresso? Signum: estudos da linguagem, Londrina, v.6, n.2, p.219-251, 2003b.

Gramaticalização: motivações sociais subjacentes à disseminação das inovações. Revista da ABRALIN, Curitiba, v.2, n.2, p.115-155. 2003c.

Um estudo variacionista de AÍ, DAÍ, ENTÃO e E como conectores sequenciadores retroativo-propulsores na fala de Florianópolis. 1999. $175 f$. Dissertação (Mestrado em Linguística) - Departamento de Letras, Universidade Federal de Santa Catarina, Florianópolis, 1999a. 
. Sequenciação de informações: condicionamentos linguísticos e sociais em duas regiões do Brasil. 1999. Trabalho final do curso Sociolinguística Comparativa, Universidade Federal de Santa Catarina, Florianópolis, 1999b. Mimeografo.

Recebido em setembro de 2010.

Aprovado em novembro de 2010. 
